\title{
Ablativo de gerundio «anterior» en la Crónica mozárabe
}

\author{
Jana Mikulová \\ Universidad de Masaryk, Brno, República Checa \\ jmikulova@gmail.com
}

\section{Anterior ablatives of the gerund in the Mozarabic Chronicle}

\begin{abstract}
En la Crónica mozárabe de 754 aparecen ablativos de gerundio que pueden interpretarse como anteriores al predicado principal. Esta interpretación se basa, sobre todo, en las características aspectuales y el contexto. El uso del ablativo de gerundio «anterior» demuestra el acercamiento entre el participio de presente y el ablativo de gerundio en latín tardío. El ablativo de gerundio «anterior», sin embargo, no aparece con frecuencia en textos de la época.
\end{abstract}

Palabras clave: ablativo de gerundio; anterioridad; Crónica mozárabe; latín tardío.
In the Mozarabic Chronicle of 754, there are ablatives of the gerund that can be interpreted as anterior to the main predicate. Aspectual characteristics and context are considered to be the main factors for the previous interpretation. The use of the anterior ablative of the gerund gives evidence of the approximation between the present participle and the ablative of the gerund in Late Latin. The anterior ablative of the gerund, however, does not seem to be frequently used in contemporary texts.

Key words: ablative of the gerund; anteriority; Mozarabic Chronicle; Late Latin.

El presente artículo estudia los ablativos de gerundio que hacen referencia al sujeto de la oración, desempeñan la función de complemento circunstancial y pueden interpretarse como anteriores a la acción del verbo finito. Por ello, omitiremos las construcciones absolutas de ablativo de gerundio (documentadas marginalmente) y los sintagmas formados por un nombre y un adjetivo con el sufijo -ndo-.

Los ablativos de gerundio «anteriores» estudiados se han tomado de la Crónica mozárabe de $754^{1}$. Hemos hecho un sondeo para comparar los resultados obtenidos con textos del Corpus Scriptorum Muzarabicorum que datan del mismo siglo y con textos que aparecen en la edición electrónica de los Monumenta Germaniae Historica (MGH), de la serie Scriptores.

\footnotetext{
${ }^{1}$ Hemos utilizado la edición de la traducción realizada por López Pereira 1980.
} 
Hemos examinado, sobre todo, los factores responsables de la lectura anterior del ablativo de gerundio en -ndo. Consideramos anteriores las acciones que empiezan y terminan antes de la acción del predicado principal ( $\mathrm{v}$. Traina 1993, pp. 231 y 307), incluidas aquellas en las que el punto final va seguido del resultado de la acción. No hemos considerado anteriores aquellas acciones que empiezan pero no terminan antes de la acción del predicado principal. Sin embargo, algunos ablativos de gerundio no tienen lectura unívoca.

Basándonos en la literatura secundaria mencionamos algunos datos sobre el gerundio «anterior» en español antiguo.

\section{EL SIGNIFICADO DEL SUFIJO -NDO-}

Los investigadores (Joffre 1995, pp. 375, 378; Christol 1999, p. 120; Vester 1991, p. 303) coinciden en que el sufijo -ndo- no tiene significado implícito de tiempo ni de modo. Los lingüistas difieren con respecto a si el sufijo -ndo- expresa solamente la acción del verbo, o sea, la idea verbal (Touratier 1994, p. 164), o el dinamismo de la acción y su desarrollo hacia el punto final (Joffre 1995, p. 386; Vester 1991, p. 303).

Mellet y Joffre 1994, pp. 382-383, afirman que el gerundio representa la acción como abierta y prospectiva y que su significado básico está reforzado en algunos contextos y debilitado en otros. A este significado básico se debe, según ellos, el dinamismo del ablativo de gerundio. Joffre 1995, p. 379, y Carvalho 2001, p. 319, comparan el sufijo -ndo- con el sufijo -to- y dicen que el gerundio no expresa acciones terminadas ni acciones ya realizadas. Carvalho (ibíd.) señala que el gerundio deriva del infectum. Maiden utiliza los mismos argumentos en su artículo sobre los gerundios romances (Maiden, 1996, p. 174). Afirma que se pueden relacionar con el aspecto imperfectivo, porque, entre otras cosas, se forman más bien a partir de temas latinos imperfectivos que de perfectivos.

Por lo tanto, en casos concretos, el significado de las formas en -ndo- no lo determinan las características implícitas del sufijo, sino los factores externos. Vester 1983, p. 109 ss., indica que en latín clásico el ablativo de gerundio suele expresar modo, instrumento o causa y que existe una relación estrecha entre el valor semántico del gerundio y el estado de cosas. El significado del ablativo de gerundio está mucho más determinado que el del participio de presente (v. Vester 1983, pp. 121-123). Para el estudio del latín tardío 
es importante el solapamiento funcional del ablativo de gerundio con el participio de presente, cuyos principios están atestiguados ya en algunos textos de la época clásica (v. Maraldi 1994, p. 142 y Vester 1991, p. 305 s.). Así pues, los ablativos de gerundio «anteriores» pueden relacionarse con los participios de presente que expresan anterioridad. Estos son, sin embargo, mucho más frecuentes que los ablativos de gerundio «anteriores».

\section{FACTORES DE LA INTERPRETACIÓN}

A continuación examinamos los factores que pueden influir en la interpretación anterior de los gerundios. Se trata, sobre todo, de las características aspectuales y del contexto.

\section{Aspecto y problemas relacionados}

El aspecto y los estados de cosas han sido objeto de muchos estudios. Nos hemos basado, sobre todo, en el concepto propuesto por Smith 1997 y aplicado al latín por Haverling 2000. Según Smith 1997, p. 4, el aspecto es más bien una característica de toda la oración que de los verbos o frases verbales. Distingue $^{2}$ el aspecto del punto de vista (viewpoint aspect), expresado por las categorías gramaticales, y el aspecto situacional (situation aspect), expresado por la constelación verbal relacionada con un tipo de situación (situation type). Los tipos de situación son grupos de situaciones idealizadas que expresan el verbo y sus argumentos, o sea, lo que se conoce como constelación verbal ${ }^{3}$. Se trata, pues, de un concepto comparable al de los estados de cosas. A partir de aquí utilizaremos el término «estado(s) de cosas» en vez de «tipo de situación», porque es más habitual. Asimismo, utilizaremos el término «aspecto gramatical» para referirnos al punto de vista. Smith 1997, p. 6 ss. y pássim, enfatiza el papel del hablante y de la subjetividad. El hablante relaciona una situación real con la idealizada y destaca un rasgo de la acción. La selección de la expresión aspectual depende de la gramática de cada lengua y sus convenciones pragmáticas. El hablante puede unir un aspecto gramatical y un estado de cosas no solo de manera estándar, sino también de una manera

2 Smith 1997, p. 5.

${ }^{3}$ Smith 1997, p. 17. 
menos usual con el fin de conseguir un efecto especial que podría influir en la veracidad de la oración.

Los criterios utilizados para establecer la tipología de los estados de cosas son dinamismo, telicidad y duración (v. Smith 1997, p. 19). A diferencia de Vester $^{4}$, Smith ${ }^{5}$ no utiliza el parámetro del control como criterio básico de su clasificación. Distingue cinco estados de cosas (Smith 1997, pp. 23-36); para cuatro de ellos utiliza los términos vendlerianos y añade los semelfactivos como un estado de cosas especial. Además de los estados de cosas básicos, Smith 1997, p. 48 ss., distingue también los estados de cosas derivados. Según Smith 1997, p. 53, en caso de conflicto entre la constelación verbal y el aspecto gramatical u otro elemento externo (p. ej. el adverbio), el elemento externo cambia el estado de cosas.

Los parámetros más importantes para la lectura anterior o simultánea de los ablativos de gerundio son telicidad, duración y momentaneidad. Según Smith 1997, p. 19, los estados de cosas télicos expresan un cambio de estado que es el resultado u objetivo de la acción verbal, y tienen un punto final inherente. Los estados de cosas atélicos expresan procesos sin resultados que pueden ser interrumpidos en cualquier momento y que tienen un punto final arbitrario.

La telicidad es un término discutido y, por eso, varios autores tratan de evitarlo. Haverling 2000, p. 22 ss., por ejemplo, opta por los términos «terminativo» $\mathrm{y}$ «no terminativo». También la momentaneidad y su relación con la telicidad son objeto de discusiones entre los especialistas. Este tema no lo trataremos en el presente artículo.

Según Smith 1997, p. 26 y 30, el rasgo «télico» aparece en los logros (accomplishments) y las realizaciones (achievements) y el rasgo «momentáneo» en las realizaciones y los semelfactivos (ibíd., pp. 29-30). Haverling 2000 , pp. 22-36, trata de unir diferentes conceptos. Utiliza categorías vendlerianas, pero dice que se trata de una clasificación aproximativa y que los semelfactivos no pertenecen a ninguna categoría (ibíd., p. 24). Las realizaciones son, según Haverling, momentáneas y terminativas (= télicas), porque en la mayoría de los casos suponen fases anteriores a la realización de la acción (ibíd., p. 39).

${ }^{4}$ Vester 1983, p. 10.

${ }^{5}$ Smith 1997, p. 19. 
Las pruebas para establecer el estado de cosas en latín se enumeran en la obra de Vester 1983, pp. 11-36, que también explica por qué es difícil o imposible aplicar al latín algunas pruebas utilizadas para el inglés (v. Vester 1983, pp. 9-36) ${ }^{6}$. Haverling 2000, p. 43 ss., añade una prueba más: el uso de los diferentes estados de cosas en las oraciones temporales introducidas por la conjunción dum. La adjudicación de una predicación concreta a un estado de cosas no suele ser unívoca. Smith 1997, pp. 56-59, afirma también que algunas constelaciones son típicamente ambiguas (p. ej., las constelaciones de los verbos de percepción). Las dificultades pueden causarlas también los problemas de carácter crítico-textual.

En la Crónica mozárabe aparecen más de diez ablativos de gerundio que podrían interpretarse como anteriores. La interpretación de algunos gerundios es, sin embargo, ambigua.

Los estados de cosas de los gerundios «anteriores» tienen a menudo las características [+ télico] y/o [+ momentáneo]. Así pues, se trata de logros, realizaciones o semelfactivos, como, por ejemplo, patrem effugiendo (1), Toleto urbem regiam usque inrumpendo (2), cuncta disponendo (3), repatriando (4), fideiussores dando (5).

1. ... filiusque Cosdroe regis Persarum, patrem tumultualiter effugiendo principi se dedit Romano... (Chron. Muz. 2).

... y el hijo del rey persa Cosroes, en medio del tumulto, huye de su padre, se pasa al general romano... (López Pereira 1980, p. 25).

2. ... Toleto urbem regiam usque inrumpendo adiacentes regiones pace fraudifica male diuerberans nonnullos seniores nobiles uiros, qui utqumque remanserant, per Oppam filium Egiche regis a Toleto fugam arripientes gladio patibuli iugulat et per eius occasionem cunctos ense detruncat (Chron. Muz. 54).

... Después de arrasarla (sc. España) hasta Toledo, la ciudad regia, y azotar despiadadamente las regiones circundantes con una paz engañosa, valiéndose de Opas, hijo del rey Egica, condena al patíbulo a algunos ancianos nobles, que aun quedaban después de haber huido de Toledo, y los pasa a espada a todos con su ayuda (López Pereira 1980, p. 71).

${ }^{6}$ Sobre la necesidad de modificar las pruebas para una lengua concreta habla también Smith 1997, pp. 39-59. 
3. Sicque cuncta obtime disponendo et Trinacrios portus preuigilando proprie sedi clementer se sublimant (Chron. Muz. 82).

Así, después de disponerlo todo convenientemente, y dejando cuidadosamente vigilados los puertos trinacrios, se incorpora indulgente a su trono (López Pereira 1980, p. 105).

4. Abdallaziz filium linquens in locum..., Vlit regis repatriando sese presentat obtutibus anno regni eius extremo (Chron. Muz. 56).

... dejando en su lugar a su hijo Abdelaziz, regresa a su patria y se presenta ante el Califa Ulit en el último año de su reinado (López Pereira 1980, p. 75).

5. Sicque fideiussores dando per suos libertos congeriem nummorum dinumerat... (Chron. Muz. 57).

Así, después de dejar fiadores, por medio de sus libertos reúne la cantidad de dinero... (López Pereira 1980, p. 77).

Las actividades están documentadas de forma más bien marginal, por ejemplo preuigilando (3). También la expresión tractando (librum) (6) puede considerarse una actividad, si tiene el significado de 'pensar / meditar sobre el libro'. Si, por el contrario, tiene el significado de 'examinar el libro' o 'explicar el libro', se trata de un logro. Entre los ejemplos no se encuentran los estados, al igual que en latín clásico (v. Vester 1983, p. 105).

6. Eius in tempore librum de tribus substantiis, quem dudum Romam sanctissimus Iulianus urbis regie metropolitanus episcopus miserat et minus tractando papa Romanus arcendum indixerat... (Chron. Muz. 41).

En su tiempo, el virtuosísimo Julián, obispo metropolitano de la ciudad regia, había ya enviado a Roma el libro Las Tres Substancias en Cristo ... y el Papa de Roma, leyéndolo sin atención, había indicado que debía ser rechazado... (López Pereira 1980, p. 61).

Los estados de cosas de los verbos finitos están caracterizados, en la mayoría de los casos, por los parámetros [+ télico] y/o [+ momentáneo]. Sin embargo también aparecen las actividades, como, por ejemplo flagellat (7). La expresión regnum retemtat (8) puede considerarse ambigua, a nuestro modo de ver: si se hace hincapié en la acción de retener el poder, se trata de un logro; si se hace hincapié en el hecho de estar en el poder, se trata de una actividad. 
7. ... alligatos in carcere et katenis honustos retemptat et quaestionando uel diuersas penas inferendo flagellat (Chron. Muz. 64).

... y los (sc. moros) guarda engrillados en la cárcel, cargados de cadenas ... Así, después de inculparlos e imponerles diversas penas, los manda azotar (López Pereira 1980, p. 81).

8. In Spaniis uero Alaor supra iam dictus Patriciam Cordobam ob seditas Saracenorum disponendo regnum retemtat... (Chron Muz. 64).

En España el ya nombrado Alaor, organizando Córdoba la Patricia mediante guarniciones de soldados sarracenos, se mantiene en el poder... (López Pereira 1980, p. 81).

Aunque los rasgos [+ télico] y [+ momentáneo] en los gerundios y en los verbos finitos parecen tener importancia para la lectura anterior, es necesario tener en cuenta también el aspecto gramatical. Como el sufijo -ndo- no expresa, por sí mismo, las acciones terminadas o realizadas y el gerundio se forma a partir del tema del infectum (v. supra), se pueden suponer las consecuencias de la combinación de un estado de cosas télico con el aspecto gramatical imperfectivo. Así se puede enfocar, por ejemplo, el intervalo precedente al cumplimiento de la acción en las realizaciones (v. Smith 1997, p. 75).

Las características mencionadas del gerundio pueden contribuir a que bajo ciertas condiciones sea posible la lectura simultánea y anterior. Por ejemplo, el gerundio effugiendo (1) podría interpretarse como simultáneo ('durante la fuga') o anterior ('después de la fuga'). Igualmente diuersas occasiones machinando (10) puede leerse, fuera del contexto, como 'al buscar diversas oportunidades' y 'después de buscar diversas oportunidades'.

Los verbos finitos ${ }^{7}$ de las oraciones analizadas aparecen tres o cuatro veces en perfecto y una vez en pluscuamperfecto; y el resto de los verbos están en presente histórico. No aparece el imperfecto. El uso del presente histórico es frecuente en toda la obra; por lo que no se trata de una característica típica de las oraciones con gerundio «anterior» ${ }^{8}$. El presente histórico puede

${ }^{7}$ En la cuestión del aspecto verbal en latín partimos de la opinión de que el tiempo verbal tiene características temporales y aspectuales (v. Bertinetto 1997, p. 20) y que el tiempo verbal en latín es más importante que el aspecto (para la recapitulación del tema, v. Haverling 2000, p. 9 ss.).

${ }^{8}$ El frecuente uso del presente histórico en algunos textos es solamente una cuestión estilística o una convención literaria, v. Pinkster 1998, p. 76, y Pinkster 1983, p. 312. 
sustituir al perfecto o al imperfecto y así se pierde la oposición aspectual (v. Comrie 1976, p. 73). En los ejemplos analizados el presente histórico aparece en la enumeración de los eventos y sustituye al perfecto. La elección de perfecto o presente histórico no influye en la interpretación anterior del gerundio.

En resumen, se puede observar la prevalencia de los estados de cosas télicos y/o momentáneos en los gerundios y los predicados principales. Para la interpretación simultánea o anterior parece ser importante la (im)posibilidad de que coincidan las fases internas del estado de cosas del gerundio y del verbo finito. Es notable la ocurrencia de los gerundios «anteriores» en las oraciones en las que se relata la sucesión de los hechos. El gerundio puede, por su índole, contribuir a la lectura ambigua.

\section{Contexto}

Otro factor importante es el del contexto amplio o restringido. La lectura anterior del gerundio repedando (9) se basa, por ejemplo, en la información sobre el regreso de Ulit que aparece en la oración precedente.

9. Quem et Dei nutu iratum repperit repedando et male de conspectu principis ceruice tenus eiicitur pompizando (Chron. Muz. 56).

Quiso Dios que, al regresar, encontrara a Ulit airado contra él y para humillarle fue expulsado de mala manera de su vista montado en un asno para que sirviera de burla (López Pereira 1980, p. 75).

La interpretación anterior del gerundio está condicionada por el contexto también en la oración (10). Al final de la oración precedente aparece la información sobre la preparación de la trampa y el verbo machinant. La interpretación anterior está reforzada por el adverbio ilico 'enseguida'.

10. Denique ubi hoc diuersas occasiones machinando ilico impetrant... (Chron. Muz. 88)

Por fin, cuando después de buscar diversas oportunidades, encuentran una, inmediatamente...» (López Pereira 1980, p. 117)

En la oración (2), la interpretación anterior está apoyada por el uso de usque 'hasta' que indica explícitamente el límite y destaca el hecho de que 
el gerundio precede al verbo finito. El adverbio postremo en la oración (11) establece el orden cronológico de los hechos y contribuye así a la lectura anterior del gerundio?.

11. Unde et eos conprehensos aliquandiu diuersas rebellionis occasiones flagellis extorquens, ut clam iussus ab emulis transmarinis fuerat, penas inferendo, postremo capite truncat (Chron Muz. 78).

Como consecuencia de ello, los hace prisioneros y después de someterlos durante algún tiempo a los tormentos de látigo, para averiguar, mediante torturas, los diversos pormenores para la rebelión, los decapita, según le había sido ordenado secretamente por sus aliados del otro lado del mar (López Pereira 1980, p. 93).

La lectura anterior del gerundio diuidendo (12) está apoyada por el objeto directo del verbo finito (partem ex omni re mobili et inmobili), que destaca que el sorteo se realizó primero y la entrega de la parte de los bienes al tesoro público después.

12. ... preda et manualia uel quidquit illud est, quod olim predauiliter indiuisum retemtabat in Spania gens omnis Arabica, sorte sociis diuidendo partem ex omni re mobili et inmobili fisco adsociat (Chron. Muz. 69).

Sortea entre sus aliados campos y ganados, así como cualquier otra cosa que los Árabes conservasen en España aun sin repartir, fruto de los anteriores botines. Al Tesoro Público entrega parte de todos los bienes muebles e inmuebles (López Pereira 1980, p. 85).

En la oración (13), el objeto directo superbos exercitus, común al gerundio y al verbo finito favorece la interpretación anterior del gerundio, porque así está claro que los ejércitos fueron primero sometidos y después enviados para luchar.

13. Tunc Abulcathar ... transmarinis partibus nec mora superbos Hispaniae domando sub nomine prelii mittit exercitus (Chron. Muz. 88).

${ }^{9}$ A diferencia del traductor, creemos que tanto el participio como el gerundio se refieren al sujeto de la oración y que el gerundio no expresa el modo de la acción del participio. El participio ya está determinado por el complemento circunstancial de modo flagellis y, además, está separado de penas inferendo por la oración subordinada. 
Abulcatar ... sometiendo inmediatamente a los turbulentos ejércitos de España, los envía allende los mares con el pretexto de una guerra (López Pereira 1980, p. 115).

Otro factor de carácter contextual es la coordinación de dos gerundios, que puede contribuir a que los dos se interpreten como anteriores o simultáneos, si no lo prohíben otros factores. En la oración (3), la coordinación del gerundio preuigilando con el gerundio disponendo, que es télico y anterior al predicado principal, apoya, a nuestro modo de ver, la lectura anterior del preuigilando con el sentido de 'dejar vigilar' u 'organizar la vigilancia'. Como en la Crónica mozárabe no aparece la coordinación del gerundio o del participio de presente con el verbo finito, no suponemos probable la coordinación del disponendo con el predicado se sublimat, lo cual sería un argumento a favor de la lectura simultánea.

En la Crónica mozárabe aparecen también los participios de presente que están situados en el mismo nivel de la oración que los ablativos de gerundio anteriores, por ejemplo, extorquens (11) o diuerberans (2). Se trata, en nuestra opinión, de muestras de la aproximación entre el participio de presente y el ablativo de gerundio.

La (im)posibilidad o la (im)probabilidad de la interpretación simultánea o anterior se basa, también, en el conocimiento del mundo por parte del emisor y el receptor. A menudo se prefiere una de las interpretaciones, aunque la otra no queda necesariamente descartada. Por ejemplo, en (6) se nos viene antes a la mente la interpretación 'después de leer el libro' que la interpretación 'durante la lectura del libro'.

Igualmente, en la oración (7) preferimos interpretar los gerundios como anteriores, porque no consideramos probable que la inculpación, la imposición de diversas penas y el azotamiento tengan lugar al mismo tiempo.

La interpretación del gerundio belligerando en la oración (14) es difícil por varias razones.

14. ... (Vlit) quatuor per annos belligerando gentes, iam regno agendo multis honoribus preditus triumphat per annos VIIII (Chron. Muz. 51).

... empeñado en la labor de ensanchar su reino en lucha con otros pueblos durante cuatro años, vive (sc. Ulit) colmado de honores nueve años de constantes triunfos (López Pereira 1980, p. 67). 
Aparece allí un lugar oscuro regno agendo con variantes textuales y conjeturas (v. López Pereira 1980, pp. 66-67). El gerundio belligerando es una actividad, pero la expresión temporal quatuor per annos le otorga las características de una oración télica (v. Smith 1997, pp. 23-25). El sintagma de gerundio en combinación con el predicado principal triumphat, acompañado de la expresión temporal per annos VIIII, parece expresar anterioridad. La duración del reinado de Ulit ${ }^{10}$ sería, entonces, de 13 años. La Crónica bizantina-arábiga, fuente de la Crónica mozárabe, dice que Ulit estuvo en el poder nueve años y después pasa a describir su reinado con más detalle. El autor de la Crónica mozárabe sigue este esquema y copia frases enteras, pero añade más datos, como, entre ellos, información sobre la duración de las luchas. La discrepancia entre las fechas se puede deber, en nuestra opinión, a las dificultades del autor a la hora de construir el texto. Martín 2006, pp. 6-7, afirma que ya el autor de la Crónica bizantina-arábiga «parece tener serias dificultades para expresarse en un latín escrito mínimamente correcto». Esta observación es aun más válida para el latín de la Crónica mozárabe. Nos parece posible que con el predicado principal triumphat el autor quiera referirse al reinado en su conjunto y con el gerundio belligerando solamente a una de sus partes. La corrupción de los manuscritos hace la explicación de este pasaje más difícil. Partiendo solamente del texto conservado creemos, sin embargo, que es posible considerar belligerando como anterior al predicado principal.

A nuestro modo de ver, la existencia de los gerundios «anteriores» no puede explicarse solamente como un mero error casual o como la incapacidad del autor para utilizar y compilar bien sus fuentes. Los gerundios «anteriores» están en consonancia con la tendencia a la aproximación gradual entre el ablativo de gerundio y el participio de presente (cf. supra). Nótese que en la oración (1) aparece el gerundio effugiendo, mientras que en la Crónica bizantina-arábiga aparece el participio de presente fugiens ${ }^{11}$.

${ }^{10}$ Walid I, que reinó entre 705-715 (v. Martín 2006, p. 18, n. 58).

${ }^{11}$ Filius quoque Cosdroe Persarum regis patrem fugiens principi se Romano obtulit... (Chron. Byz.-Arab. 10). «El hijo del rey persa Cosroes huyó de su padre y se entregó al general romano...» 


\section{Orden de los constituyentes}

Los gerundios que se pueden interpretar como anteriores, preceden, en la mayoría de los casos, al verbo finito. Solamente el gerundio repedando (9) está pospuesto, aunque su valor semántico queda claro a partir del contexto. Los otros gerundios pospuestos documentados en la Crónica no expresan anterioridad; este es el caso, por ejemplo, de peruenit nauigando (Chron. Muz. 1). La misma tendencia se puede observar en los participios de presente «anteriores».

\section{Gerundio ANTERIOR en Otros textos}

Al hacer una búsqueda en los textos del mismo territorio y de la misma época, o de un territorio y época cercanos, hemos averiguado que el uso de los gerundios «anteriores» no es habitual. Hemos examinado los textos del Corpus Scriptorum Muzarabicorum, datados en el siglo VIII, y los textos de la edición electrónica de los $M G H$, procedentes de los siglos VII y VIII. Los ejemplos de los gerundios anteriores son muy escasos y no pasan de diez. La escasez de ejemplos se puede deber también al género de la obra. Este es el caso de los tratados teológicos (que conforman, en gran parte, el Corpus), cuyo objetivo no es la descripción cronológica de los eventos. Sin embargo estos también se encuentran con poca frecuencia en textos narrativos de carácter historiográfico. La interpretación de los gerundios es a menudo ambigua y la lectura anterior se establece a partir del contexto. En el ejemplo tomado de Paulo Diácono ${ }^{12}$ aparece el gerundio uidendo, de estado de cosas típicamente ambiguo (v. Smith 1997, pp. 56-57), acompañado del adverbio subito 'de repente, enseguida' que indica unívocamente la sucesión de las acciones. En otro ejemplo, tomado de Ionas ${ }^{13}$, el valor de anterioridad del gerundio penetrando se deduce a partir del orden de los constituyentes y el conocimiento del mundo. Por eso es más probable la interpretación anterior

${ }^{12}$ Ille autem qui baptismum, accipere uolebat, uidendo tam novam causam subito abiit ad catholicam ecclesiam... (Paul. Diac., Hist. Rom. Excerpta Bamb., AA II, 16). «Pero cuando este, quien quería ser bautizado, vio una cosa tan nueva, enseguida se fue a la iglesia católica...»

${ }^{13}$... frater [communis] Segonus abdite fores ecclesie penetrando Dominum orationibus pulsat. (Ionas, V. Ioh. abb. Reomaensis, MGH SS rer. Germ. XXXVII, 14) «... el fraile Segono entró a escondidas en la iglesia y rezó al Señor con insistencia». 
('entró en la iglesia y rezó') que la simultánea ('rezó solamente durante la entrada en la iglesia').

En los textos narrativos abundan los participios de presente, incluidos los que expresan anterioridad. En los $M G H$ se encuentran también los participios de presente «anteriores» de algunos de los verbos cuyos gerundios pueden interpretarse como anteriores en la Crónica mozárabe. Se trata, por ejemplo, de los participios diuidentes (Fredeg. cont., SS rer. Merov. II, 25) o inrumpentes (Ionas, V. Columbani SS rer. Germ. XXXVII, 2, 10).

\section{COMPARACIÓN CON EL ESPAÑOL ANTIGUO}

Algunas características del gerundio en español antiguo, descritas en la obra de Muñío Valverde 1995, son muy semejantes a las características de los ablativos de gerundio anteriores en la Crónica mozárabe. Muñío Valverde 1995, pp. 92-93, observa que la coincidencia de las acciones del gerundio y el verbo principal puede ser muy limitada. Según él, en algunos contextos puede desaparecer y el gerundio puede expresar anterioridad o posterioridad real. Los gerundios simultáneos son mucho más frecuentes que los anteriores y entre los anteriores prevalecen los que expresan anterioridad inmediata. Muñío Valverde 1995, p. 97, afirma que los gerundios anteriores suelen anteponerse al verbo finito y que, en caso de posponerse, el orden cronológico de los eventos se expresa mediante otros procedimientos. Observa (ibíd., p. 94) que los factores importantes son el contexto, el lexema del gerundio y del verbo finito y el tiempo verbal del verbo finito. Es posible, por lo tanto, ver paralelos entre el uso del gerundio en español antiguo y de los ablativos de gerundio en la Crónica mozárabe.

\section{Conclusión}

La interpretación anterior de los ablativos de gerundio es resultado de la interacción de varios factores. Entre los más importantes se encuentran el estado de cosas del gerundio y del predicado principal de la oración, el aspecto gramatical, el contexto, el orden de constituyentes y también los conocimientos compartidos por el emisor y el receptor. La mayoría de los gerundios anteriores y los predicados principales correspondientes pueden clasificarse como télicos y/o momentáneos. Los verbos finitos de las oraciones analizadas aparecen en la mayoría de los casos en presente histórico, tiempo que en 
la Crónica mozárabe alterna con el perfecto en la narración de los hechos. La ausencia del morfema «terminativo» en el gerundio y su derivación del tema del infectum contribuye a la interpretación ambigua de algunos gerundios. El factor importante para la interpretación anterior de algunos gerundios es el contexto. Se puede observar una fuerte tendencia a anteponer los gerundios anteriores a los verbos finitos y a organizar las acciones cronológicamente, en consonancia con el género de la obra y con el modo de estructurar el texto en las obras historiográficas de la latinidad tardía. El receptor desempeña el papel más importante, puesto que a partir de los factores mencionados y su conocimiento del mundo es quien opta por la interpretación más probable.

La búsqueda, realizada en algunas obras del período comparable, muestra que en ellas el ablativo de gerundio «anterior» es poco frecuente y que aparecen más a menudo los participios de presente anteriores. En nuestra opinión, el uso del gerundio «anterior» en la Crónica mozárabe es una muestra del proceso de aproximación entre el ablativo de gerundio y el participio de presente. Este, al expresar anterioridad, es mucho más frecuente y tiene características comparables a las que hemos descubierto en los ablativos de gerundio estudiados. Existen también paralelos entre el uso del ablativo de gerundio en la Crónica mozárabe y en los textos en español antiguo.

\section{BiBLIOGRAFÍA}

Bertinetto, P. M. 1997: Il dominio tempo-aspettuale, Turín, Rosenberg \& Sellier.

Carvalho, P. de 2001: «Du nom (dé)verbal en -ndo/-a: "gerundivm" vs "gerundivvm"», en Moussy, C. et al. (eds.), De lingua Latina novae quaestiones: Actes du Xè Colloque International de Linguistique Latine, Paris - Sèrves, 19-23 avril 1999, Lovaina, Peeters, pp. 307-320.

Christol, A. 1999: «Autour du gérondif latin : Comment le temps vient aux noms verbaux», en Vogeleer, S. et al. (eds.), La modalité sous tous ses aspects, Ámsterdam-Atlanta (GA), Rodopi, pp. 115-133.

Comrie, B. 1976: Aspect, Cambridge, Cambridge University Press.

Gil, J. (ed.) 1973: Corpus Scriptorum Muzarabicorum I, Madrid, Instituto «Antonio Nebrija».

Joffre, M.-D. 1995 : Le verbe latin: voix et diathèse, Lovaina, Peeters.

Haverling, G. 2000: On Sco-Verbs, Prefixes and Semantic Functions: A study in the development of prefixed and unprefixed verbs from Early to Late Latin, «Studia Graeca et Latina Gothoburgensia» LXIV, Gotemburgo. 
López Pereira, J. L. (ed.) 1980: Crónica mozárabe de 754, Zaragoza, Anubar Ediciones.

Maiden, M. 1996: «The Romance gerund and 'system dependent naturalness' in morphology», Transactions of the Philological Society 94, 2, pp. 167-201.

Maraldi, M. 1994: "Some remarks on the historical development of the ablative of the gerund in Latin», en Calboli, G. (ed.), Papers on Grammar IV, Bolonia, CLUEB, pp. 141-164.

Martín, J. C. 2006: «Los Chronica Byzantia-Arabica», e-Spania [En línea], 1, junio 2006, puesto en línea el 22 agosto 2010, <http://e-spania.revues.org/329> (28/04/2011).

Mellet, S., Joffre, M.-D. 1994: «Le supin et le gérondif», en Mellet, S., Joffre, M.D. y Serbat, G. (eds.), Grammaire fondamentale du latin. Le signifié du verbe, Lovaina-París, Peeters, pp. 369-384.

Monumenta Germaniae historica (MGH 8) [CD-ROM], Turnhout, Brepols, $2008^{8}$.

Muñío Valverde, J. L. 1995: El gerundio en el español medieval (s. XII-XIV), Málaga: Ágora.

Pinkster, H. 1983: «Tempus, Aspect and Aktionsart», Aufstieg und Niedergang der römischen Welt 29, 1, pp. 270-319.

Pinkster, H. 1998: «Is the Latin present tense the unmarked, neutral tense in the system?», en Risselada, R. (ed.), Latin in Use: Amsterdam studies in the pragmatics of Latin, Ámsterdam, J. C. Gieben, pp. 63-83.

Smith, C. S. 1997²: The Parameter of Aspect, Dordrecht-Boston-Londres, Kluwer.

Traina, A., Bertotti, T. 1993²: Sintassi normativa della lingua latina: teoria, Bologna, Cappelli.

Touratier, Ch. 1994: Syntaxe Latine, Lovaina-la-Nueva, Peeters.

Vester, E 1983: Instrument and Manner expressions in Latin, Assen, Van Gorcum.

Vester, E. 1991: «Reflections on the gerund and gerundive», en Coleman, R. (ed.), New Studies in Latin Linguistics. Selected Papers from the 4th Internalional Colloquium on Latin Linguistics, Cambridge, April 1987, Ámsterdam, Benjamins, pp. 295-309.

Fecha de recepción de la primera versión del artículo: 01/08/2011

Fecha de aceptación: 09/07/2012

Fecha de recepción de la versión definitiva: 07/08/2012 